${ }^{1}$ Faculty of Dentistry, Federal University of Bahia (UFBA), Salvador, BA, Brazil.

${ }^{2}$ Bahiana School of Medicine and Public Health (EBMSP), Salvador, BA, Brazil.

${ }^{3}$ Faculty of Dentistry, Feira de Santana State University (UEFS), Feira de Santana, BA, Brazil.
Corresponding author: Emilena Maria Castor Xisto Lima Av. Araújo Pinho, 72, Canela. Salvador-BA, Brazil.

CEP - 40301-155

Email: emilenalima@gmail.com

Received: July 20, 2020

Accepted: October 29, 2020

\section{Analysis of the marginal adaptation of different crowns fabricated with computer-aided technology using an intraoral digital scanner}

Roniel Kappler ${ }^{1}$, Michelle Villa Oliveira ${ }^{2}$, Ingrid de Oliveira Bandeira ${ }^{2}$, Thayara Coelho Metzker ${ }^{2}$, Adriana Oliveira Carvalho ${ }^{2,3}$, Emilena Maria Castor Xisto Lima ${ }^{1,2, *}$ (i)

Aim: The aim of this study was to evaluate the marginal adaptation of ceramic and composite resin crowns fabricated with computer-aided design and computer-aided manufacturing (CAD/CAM) technology using an intraoral digital scanner. Methods: A human mandibular right second molar was prepared for a ceramic crown. The impressions were made using intraoral scanning device and crowns were milled. Ten crowns were fabricated for each group ( $n=10)$ : GF - Feldspathic Ceramic (Cerec Blocs, Sirona), GL - Lithium Disilicate Ceramic (IPS e.max CAD, Ivoclar), GG - composite resin (Grandio Blocs, VOCO) and GB - composite resin (Brava Block, FGM). The marginal gap was measured for each specimen at 4 points under magnification with a stereomicroscope. All data were statistically analyzed using one-way ANOVA followed by the Tukey's test $(a=.05)$. Results: The lowest marginal discrepancy value was observed in GB $(60.95 \pm 13.64 \mu \mathrm{m})$, which was statistically different from the GL $(84.22 \pm 20.86 \mu \mathrm{m})$. However, there was no statistically significant difference between these groups when compared with the other groups, GF (73.26 \pm $8.19 \mu \mathrm{m})$ and GG $(68.42 \pm 11.31 \mu \mathrm{m})$. Conclusion: It can be concluded that the composite resin presented the lowest variance compared to the lithium disilicate glass ceramic, although the marginal gap of all materials tested was within the acceptable clinical limit $(120 \mu \mathrm{m})$.

Keywords: Computer-aided design. Crowns. Dental marginal adaptation. Ceramics. Composite resins. 


\section{Introduction}

In recent years, newer technologies have been developed in dentistry with the purpose of improving the outcome of indirect restorations ${ }^{1}$. As the name suggests, the computer-aided design and manufacturing (CAD/CAM) system is an innovative technology, wherein planning and fabrication of prostheses are performed using a computer $^{2}$. With this technology, it is possible to create a virtual model of the prosthetic preparation, occlusal relationship of the arches, and plan the restoration. After virtual planning, fabrication of the restoration is carried out without intermediate manufacturing steps, thereby decreasing the cost, time, and risk of contamination during the interim restoration phase ${ }^{3}$

There are two main types of dental CAD/CAM scanners namely intraoral and extraoral scanners. Intraoral scanners are used chairside to scan the dental arches of patients; while extraoral scanners are used in the dental laboratory to scan casts ${ }^{4}$. The extraoral technique may lead to errors during the final impression stage and master cast production. Intraoral scanners aim to eliminate dimensional changes of the impression materials and expansion of the dental stone ${ }^{5,6}$; however, certain factors in the oral environment, such as saliva, sulcular fluid, patient movement, or limited space may interfere in obtaining the digital model ${ }^{7,8}$. In order to be considered an acceptable alternative to conventional impression methods, intraoral scanning devices should yield crowns with similar or better clinical success ${ }^{3,9}$.

For the success of prosthetic crowns, good marginal adaptation is essential9-11. Marginal gap can be defined as the distance from edge of the finish line of the prepared tooth to cervical margin of the restoration ${ }^{12}$. Presence of marginal gaps contributes to exposure of cement to the oral environment, thereby raising the possibility of dissolution, biofilm accumulation, secondary caries, pulp and periodontal inflammation ${ }^{10,13-15}$ Reference values for a clinically acceptable marginal discrepancy have been described in the literature as less than $120 \mu^{16}$, and the recommended threshold for CAD/CAM crowns is between 50 and $100 \mu \mathrm{m}^{17-20}$.

Several factors may influence marginal adaptation, including design of the preparation, location of the margin, impression and waxing techniques ${ }^{21}$, accuracy of the milling system, size of the milling bur, thickness of the cementation space and restorative material ${ }^{22,23}$. As chairside CAD/CAM technology is gaining a foothold in dentistry, several restorative materials such as ceramics and composite resins are being increasingly developed and marketed ${ }^{24}$.

Ceramics are highly aesthetic, with optical characteristics of translucency and opalescence superior to resinous materials. Moreover, ceramics have high fracture resistance and low material wear 25,26 ; however, may have a potential abrasive effect on opposing dentition ${ }^{27}$. Resin composites consist of a polymeric matrix reinforced by fillers that could be inorganic (ceramics, glass-ceramics, or glasses), organic, or composite 28,29 According to Awada et al. ${ }^{24}$ (2015) polymer-based materials appear capable of producing acceptable margins with more conservative preparations, possibly due to relatively high flexural strength combined with low flexural modulus. Polymer-based materials appear to exhibit smoother milled margins compared to ceramic materi- 
als $^{24}$. In addition, resinous composites are easy to fabricate, repairable intraorally, and allow for less visible intra-oral repair of minor defects induced by function ${ }^{29}$.

There are controversial data in the literature regarding marginal adaptation of crowns fabricated with resin composites and lithium disilicate ceramics. A study by de Paula Silveira et al. ${ }^{2}$ (2017) showed no difference among these materials. Tabata et al. ${ }^{1}$ (2020) found that the composite resin presented significantly lower values of marginal discrepancy $(56 \pm 27 \mathrm{~mm})$ than ceramic $(71 \pm 35 \mathrm{~mm})$, however, El Ghoul et al. ${ }^{30}(2020)$ reported that ceramic-based groups showed smaller gaps than resin-based groups.

Further studies are required on marginal adaptation of CAD/CAM restorative materials considering the lack of sufficient data. Thus, the purpose of this in vitro study was to evaluate the marginal adaptation of ceramic and composite resin crowns fabricated with CAD/CAM technology using intraoral digital scanner. The null hypothesis was that marginal adaptation values of crowns are not influenced by the type of material.

\section{Material and methods}

The Research Ethics Committee of the Faculty of Dentistry of the Federal University of Bahia approved this study (number 3,082,332). One caries-free human mandibular molar was selected, cleaned by scaling, and stored in $0.01 \%$ Thymol to prevent bacterial proliferation. The tooth was stored in a metal box with a damp sponge to prevent it from drying and becoming brittle, throughout the study.

The human mandibular right second molar was mounted with its adjacent teeth on a typodont and prepared to receive an all-ceramic crown with chamfer finish line. The tooth preparation was as follows: $2 \mathrm{~mm}$ reduction of the occlusal surface, convergence angle of approximately 6 degrees, 1.0 to $1.5 \mathrm{~mm}$ axial reduction, and location of the finish line was above the cementoenamel junction. Diamond tips were used for the tooth preparation adapted on a multiplier contra-angle T3-Line handpiece (Sirona Dental Systems $\mathrm{GmbH}$, Bensheim, Germany) in the following sequence: diamond tip FG 3216 (KG Sorensen, Cotia, Brazil) for delimitation of the buccal, lingual and occlusal orientation grooves and union of the grooves, diamond tip FG 3203 (KG Sorensen, Cotia, Brazil) was used to make contact point rupture, FG 3216 (KG Sorensen, Cotia, Brazil) was used to create a chamfer finish line and diamond tip FG 4138 was used for finishing (KG Sorensen, Cotia, Brazil).

The composition and information regarding manufacturer of the tested materials are listed in Table 1.

Table 1. Type, composition, and manufacturer of the four tested materials

\begin{tabular}{|c|c|c|}
\hline Material & Composition & Manufacturer \\
\hline CEREC Blocs & Feldspathic Ceramic - GF & $\begin{array}{l}\text { Sirona (Bad Säckingen - Bensheim - } \\
\text { Germany) }\end{array}$ \\
\hline IPS e.max CAD & Lithium Dissilicate Glass Ceramic - GL & Ivoclar Vivadent (Schaan - Liechtenstein). \\
\hline Grandio Blocs & Resin composite (hybrid nano ceramic) - GG & VOCO (Cuxhaven - Germany) \\
\hline Brava Block & $\begin{array}{l}\text { Resin composite (glass ceramic } \\
\text { composite) - GB }\end{array}$ & FGM (Joinville - Santa Catarina - Brazil) \\
\hline
\end{tabular}


Ten digital impressions of the prepared tooth were made for each group using the CEREC Omnicam intraoral scanner (Sirona Dental Systems GmbH, Bensheim, Germany). The appropriate software CEREC inLab SW 4.5 (Sirona Dental Systems GmbH, Bensheim, Germany) was used to design the crowns on the virtual model. The operator determined design parameters were as follows: radial and occlusal spacer $=80 \mu \mathrm{m}$, resistance of proximal contacts $=-25 \mu \mathrm{m}$, resistance of occlusal contacts $=-25 \mathrm{~mm}$, dynamic contact force $=-25 \mu \mathrm{m}$, minimum thickness $($ radial $)=700 \mu \mathrm{m}$, minimum thickness $($ occlusal) $=900 \mu \mathrm{m}$, and margin thickness $=80 \mu \mathrm{m}$. All restorations were designed to have similar occlusal anatomy and the same occlusogingival height. After each crown was designed, the information was exported to the milling unit CEREC inLab MCXL ((Sirona Dental Systems GmbH, Bensheim, Germany).

Ten crowns were fabricated for each group $(n=10)$ : GF - Feldspathic Ceramic, GL - Lithium Disilicate Ceramic, GG - composite resin (Grandio Blocs) and GB - composite resin (Brava Block). Following the manufacturers' instructions, specimens in group GL were subjected to the crystallization process (Programat CS2; Ivoclar Vivadent, Schaan, Liechtenstein), while specimens in GF, GG and GB groups did not need any crystallization firing.

\section{Analysis of marginal discrepancy}

The crowns were adapted to the prepared dental unit (mandibular right second molar) with the aid of a " $\mathrm{C}$ " clamp and maintained in a standardized position during the analysis in a stereomicroscope lupe ${ }^{31}$ (Optima MDCE-5a 2.0, Hiperquímica, Santo André, Brazil) (figure 1). Photographs were obtained at $45 X$ magnification from the buccal, lingual, mesial, and distal surfaces, and images were transferred to the CorelDraw X7 program. Marginal discrepancy was determined by measuring the space (marginal opening) between margin of the crowns and finish line of the human mandibular right second molar. For each crown, the measurements were made at four vertical reference lines previously marked at the midpoint of the dental unit finish line (figure 2) at four locations to represent the buccal, lingual, mesial, and distal surfaces of tooth ${ }^{32}$. The measurements were made thrice along the long axis of the tooth at each of the four reference points. The arithmetic mean of twelve readings (three on each face) was calculated for each specimen. All procedures were performed by one calibrated operator.

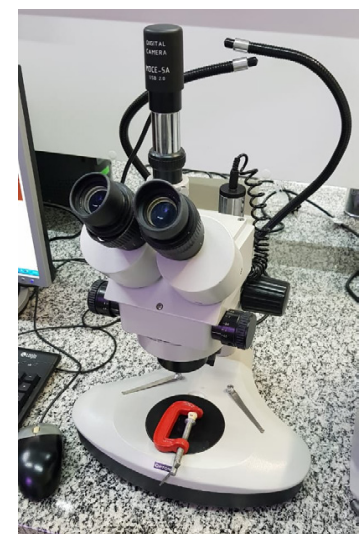

Figure 1. Crown adapted to the prepared dental unit and maintained in a standardized position during the analysis in a stereomicroscope lupe. 


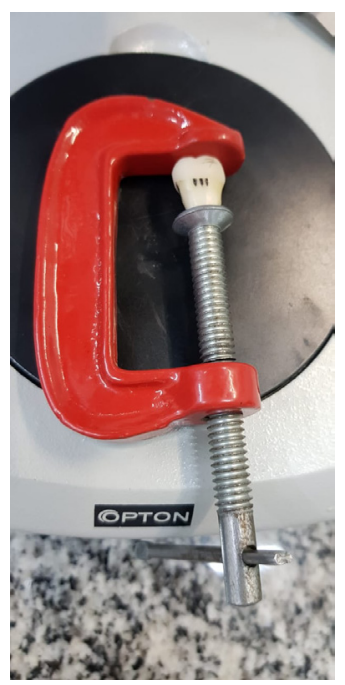

Figure 2. Crown adapted to the prepared dental unit (see vertical reference lines) with the aid of a "C" clamp.

\section{Statistical analysis}

The normality and variance homogeneity assumptions were verified using the Shapiro-Wilk and Levene tests, neither of which violated this assumption. The amounts of marginal discrepancy were compared between the four materials with the one-way analysis of variance (ANOVA) followed by the Tukey's test for multiple comparisons $(a=.05)$. The analyses were performed using the statistical program, SPSS Statistics v19.0 (IBM Corp Chicago, United States).

\section{Results}

Means and standard deviations of marginal adaptation are described in Table 2.

Table 2. Means and standard deviation (SD) of marginal discrepancy (values in micrometer - $\mu$ m) within each of four groups tested

\begin{tabular}{lcc}
\hline Group & Material & $\begin{array}{c}\text { Marginal discrepancy } \\
\text { Mean } \pm \text { SD }(\mathrm{mm})\end{array}$ \\
\hline $\mathrm{GF}$ & Feldspathic Ceramic & $73.26 \pm 18.19 \mathrm{AB}$ \\
\hline $\mathrm{GL}$ & Lithium Disilicate Ceramic & $84.22 \pm 20.86^{\mathrm{A} .}$ \\
\hline $\mathrm{GG}$ & Resin composite - Grandio Blocs & $68.42 \pm 11.31^{\mathrm{AB}}$ \\
\hline $\mathrm{GB}$ & Resin composite - Brava Block & $60.95 \pm 13.64^{\mathrm{B}}$ \\
\hline
\end{tabular}

1 -way ANOVA test and post-hoc Tukey test $(p<0.05)$. Averages followed by distinct letters represent significant differences.

The lowest marginal discrepancy value was observed in GB $(60.95 \pm 13.64 \mu \mathrm{m})$ which was statistically different from the GL $(84.22 \pm 20.86 \mu \mathrm{m})$, that showed the highest value of marginal discrepancy. However, there was no statistically significant difference 
between these groups when compared with the other groups GF $(73.26 \pm 8.19 \mu \mathrm{m})$ and GG $(68.42 \pm 11.31 \mu \mathrm{m})$. All groups showed marginal discrepancies within the clinically acceptable value.

\section{Discussion}

The null hypothesis that marginal adaptation values of crowns are not influenced by the type of material was rejected because a significant difference was observed between the lithium disilicate ceramic and composite resin (Brava Block). However, it was verified that there was no statistically significant difference when these materials were individually compared with feldspathic ceramic and composite resin (Grandio Blocs).

A gap between 50 and $100 \mu \mathrm{m}$ has been considered acceptable for adequate marginal adaptation of CAD/CAM restorations ${ }^{17-20}$. In this study, the mean value of marginal discrepancy of the four groups (GF, GL, GG, and GB) was in the range of $60.95 \pm 13,64 \mu \mathrm{m}$ to $84.22 \pm 20,86 \mu \mathrm{m}$; therefore, were clinically acceptable. Group GL displayed the largest gaps while group GB displayed the smallest gaps. Some studies ${ }^{2,24}$ have reported that resin materials demonstrated better machinability and adaptation. According to Awada et al. ${ }^{24}$ (2015) these materials tend to be less brittle and more flexible probably due to the resin component.

Tabata et al. ${ }^{1}$ (2020) evaluated the marginal adaptation of crowns fabricated with two materials (ceramic and composite resin) and two internal spacings using the CAD/CAM system. They reported statistically significant difference between materials for marginal adaptation with spacing of $80 \mu \mathrm{m}$. This result is consistent with that of the present study, wherein the same internal spacing measure was used and a difference was observed between the lithium disilicate ceramic and composite resin (Brava Block), although there was no difference between the former and composite resin (Grandio Blocs).

El Ghoul et al. ${ }^{30}$ (2020) compared the marginal adaptation of lithium disilicate ceramic crown (IPS e.max CAD) and resin composite endocrown (Cerasmat) fabricated using the CAD/CAM system and observed that there was a statistically significant difference between the tested groups. However, the composite resin crown showed higher marginal discrepancy values $(143.0 \pm 21.7 \mu \mathrm{m})$ than lithium disilicate ceramics $(104.8 \pm 14.1 \mu \mathrm{m})$. In the present study, resin composites showed smaller marginal discrepancy than the tested ceramics, with a statistically significant difference between the lithium disilicate ceramic and resin composite (Brava Block).

de Paula Silveira et al. ${ }^{2}$ (2017) evaluated the marginal adaptation of lithium disilicate (IPS e.max CAD) and composite resin (Lava Ultimate) total crowns fabricated by CAD/CAM technology using intraoral digital scanner and reported no statistically significant difference between the materials. These data partially corroborate with the present study, wherein there was no statistically significant difference between lithium disilicate ceramics and the composite resin (Grandio Blocs). However, statistically significant difference was observed when compared to the other composite resin (Brava Block). 
In the present study, photographs were taken at 45X magnification using stereoscopic magnifying glass, while in the studies by Tabata et al. ${ }^{1}$ (2020) and de Paula Silveira et al. ${ }^{2}$ (2017) the method used was microtomography. Variations may also be related to the different resin composite materials tested, namely Lava Ultimate, Cerasmat, Brava Block, and Grandio Blocs. The manufacturing method, scanning, and milling system accuracy could also influence the observations.

When comparing the materials used in the present study with those in other studies, the resin composite Grandio Blocs had $86 \%$ inorganic filler particles in a polymer matrix, but the particle size was not reported ${ }^{33}$ whereas Brava Block had $80 \%$ inorganic filler encased in a resin matrix with particle size ranging from of 40 nanometers $(\mathrm{nm})$ to $5 \mu \mathrm{m}^{34}$. In the other studies, the resin composite used (Lava Ultimate) had $80 \%$ inorganic fillers by weight with individual particles in the size range of 4 to $20 \mathrm{~nm}^{35}$. The variation in particle size may be related to the differences between the materials and results obtained.

Few other studies have compared the marginal adaptation of feldspathic ceramic crowns with other restorative materials. das Neves et al. ${ }^{36}$ (2014) evaluated the marginal adaptation of feldspathic ceramic total crowns manufactured by the CAD/CAM system and found that the marginal discrepancy was $62.6 \pm 65.2 \mu \mathrm{m}$. This was within close range of the values observed in the present study, wherein marginal adaptation of feldspathic ceramic was $73.26 \pm 18.19 \mu \mathrm{m}$.

The in vitro nature of this study could be considered a limitation, the results of which may differ from a clinical study, where the scanning and processing would be less precise due to constraints such as presence of saliva and limited access of the scanner in the oral cavity.

Within the limitations of this study, it can be concluded that the composite resin Brava Block presented the lowest variance when compared with the lithium disilicate glass ceramic, although the marginal gap of all materials tested was within the acceptable clinical limit $(120 \mu \mathrm{m})$.

\section{Acknowledgments}

The authors thank the Biochemistry laboratory of the Collective Health Institute of Federal University of Bahia for providing the stereosmicroscope lupe that was used for marginal fit and the Dentsply Sirona Company for providing the scanner and the milling machine that were used for crowns fabrication.

\section{References}

1. Tabata LF, de Lima Silva TA, de Paula Silveira AC, Ribeiro APD. Marginal and internal fit of CAD-CAM composite resin and ceramic crowns before and after internal adjustment. J Prosthet Dent. 2020 Mar;123(3):500-5. doi: 10.1016/j.prosdent.2019.01.010.

2. de Paula Silveira AC, Chaves S.B, Hilgert LA, Ribeiro APD. Marginal and internal fit of CAD-CAMfabricated composite resin and ceramic crowns scanned by 2 intraoral cameras. J Prosthet Dent. 2017 Mar;117(3):386-92. doi: 10.1016/j.prosdent.2016.07.017. 
3. Miyazaki T, Hotta Y, Kunii J, Kuriyama S, Tamaki Y. A review of dental CAD/CAM: current status and future perspectives from 20 years of experience. Dent Mater J. 2009 Jan;28(1):44-56. doi: $10.4012 / \mathrm{dmj} .28 .44$.

4. González de Villaumbrosia P, Martínez-Rus F, García-Orejas A, Salido MP, Pradíes G. In vitro comparison of the accuracy (trueness and precision) of six extraoral dental scanners with different scanning technologies. J Prosthet Dent. 2016 Oct;116(4):543-50.e1. doi: 10.1016/j.prosdent.2016.01.025.

5. Davidowitz G, Kotick PG. The use of CAD/CAM in dentistry. J Dent Clin North Am. 2011 Jul:55(3):559-70, ix. doi: 10.1016/j.cden.2011.02.011.

6. Fasbinder D. Using digital technology to enhance restorative dentistry. Compend Contin Educ Dent. 2012 Oct;33(9):666-8, 670, 672

7. Shembesh M, Ali A, Finkelman M, Weber HP, Zandparsa R. An in vitro comparison of the marginal adaptation accuracy of CAD/CAM restorations using different impression systems. J Prosthodont. 2017;26:581-582017 Oct;26(7):581-86. doi: 10.1111/jopr.12446.

8. Bohner LOL, De Luca Canto G, Marció BS, Laganá DC, Sesma N, Tortamano Neto P. Computer-aided analysis of digital dental impressions obtained from intraoral and extraoral scanners. J Prosthet Dent. 2017 Nov;118(5):617-23. doi: 10.1016/j.prosdent.2016.11.018.

9. Abdel-Azim T, Rogers K, Elathamna E, Zandinejad A, Metz M, Morton D. Comparison of the marginal fit of lithium disilicate crowns fabricated with CAD/CAM technology by using conventional impressions and two intraoral digital scanners. J Prosthet Dent. 2015 Oct;114(4):554-9. doi: 10.1016/j.prosdent.2015.04.001.

10. Felton DA, Kanoy BE, Bayne SC, Wirthman GP. Effect of in vivo crown margin discrepancies on periodontal health. J Prosthet Dent. 1991 Mar;65(3):357-64. doi: 10.1016/0022-3913(91)90225-I.

11. Demir N, Ozturk AN, Malkoc MA. Evaluation of the marginal fit of full ceramic crowns by the microcomputed tomography (micro-CT) technique. Eur J Dent. 2014 Oct;8(4):437-44. doi: 10.4103/1305-7456.143612.

12. Holmes JR, Bayne SC, Holland GA, Sulik WD. Considerations in measurement of marginal fit. J Prosthet Dent. 1989 Oct;62(4):405-8. doi: 10.1016/0022-3913(89)90170-4.

13. Hunter AJ, Hunter AR. Gingival margins for crowns: a review and discussion. Part II: Discrepancies and configurations. J Prosthet Dent. 1990 Dec;64(6):636-42. doi: 10.1016/0022-3913(90)90286-I.

14. Sailer I, Fehér A, Filser F, Gauckler LJ, LüthycH, Hämmerle CH. Five-year clinical results of zirconia frameworks for posterior fixed partial denture. Int J Prosthodont. 2007 Jul-Aug;20(4):383-8.

15. Jei JB, Mohan J. Comparative evaluation of marginal accuracy of a cast fixed partial denture compared to soldered fixed partial denture made of two different base metal alloys and casting techniques: an in vitro study. J Indian Prosthodont Soc. 2014 Mar;14(1):104-9. doi: 10.1007/s13191-013-0286-2.

16. McLean JW, Von Fraunhofer JÁ. The estimation of cement film thickness by an in vivo technique. Br Dent J. 1971 Aug;131(3):107-11. doi: 10.1038/sj.bdj.4802708.

17. Akbar JH, Petrie CS, Walker MP, Williams K, Eick JD. Marginal adaptation of Cerec 3 CAD/CAM composite crowns using two different finish line preparation designs. J Prosthodont. 2006 May-Jun;15(3):155-63. doi: 10.1111/j.1532-849X.2006.00095.x.

18. Att W, Komine F, Gerds T, Strub JR. Marginal adaptation of three different zirconium dioxide three-unit fixed dental prostheses. J Prosthet Dent. 2009 Apr;101(4):239-47. doi: 10.1016/S0022-3913(09)60047-0.

19. Euán R, Figueras-Álvarez O, Cabratosa-Termes J, Brufau-de Barberà M, Gomes-Azevedo S. Comparison of the marginal adaptation of zirconium dioxide crowns in preparations with two different finish lines. J Prosthodont. 2012 Jun;21(4):291-5. doi: 10.1111/j.1532-849X.2011.00831.X. 
20. Euán R, Figueras-Álvarez O, Cabratosa-Termes J, Oliver-Parra R. Marginal adaptation of zirconium dioxide copings: influence of the CAD/CAM system and the finish line design. J Prosthet Dent. 2014 Aug;112(2):155-62. doi: 10.1016/j.prosdent.2013.10.012.

21. Shamseddine L, Mortada R, Rifai K, Chidiac JJ. Marginal and internal fit of pressed ceramic crowns made from conventional and computer-aided design/computer-aided manufacturing wax patterns: an in vitro comparison. J Prosthet Dent. 2016 Aug;116(2):242-8. doi: 10.1016/j.prosdent.2015.12.005.

22. Boeddinghaus M, Breloer E.S, Rehmann P, Wöstmann B. Accuracy of single- tooth restorations based on intraoral digital and conventional impressions in patients. Clin Oral Investig. 2015 Nov; 19(8):2027-34. doi: 10.1007/s00784-015-1430-7.

23. Renne W, Wolf B, Kessler R, McPherson K, Mennito AS. Evaluation of the marginal fit of CAD/CAM crowns fabricated using two different chairside CAD/CAM systems on preparations of varying quality. J Esthet Restor Dent. 2015;27(4):194-202. doi: 10.1111/jerd.12148.

24. Awada A, Nathanson D. Mechanical properties of resin-ceramic CAD/CAM restorative materials. J Prosthet Dent. 2015 Oct;114(4):587-93. doi: 10.1016/j.prosdent.2015.04.016.

25. Kois DE, Isvilanonda V, Chaiyabutr Y, Kois JC. Evaluation of fracture resistance and failure risks of posterior partial coverage restorations. J Esthet Restor Dent. 2013 Apr;25(2):110-22. doi: 10.1111/jerd.12018.

26. Zahran M, El-Mowafy O, Tam L, Watson PA, Finer Y. Fracture strength and fatigue resistance of all-ceramic molar crowns manufactured with CAD/CAM technology. J Prosthodont. 2008 Jul;17(5):370-7. doi: 10.1111/j.1532-849X.2008.00305.X.

27. Sripetchdanond J, Leevailoj C. Wear of human enamel opposing monolithic zirconia, glass ceramic, and composite resin: an in vitro study. J Prosthet Dent. 2014 Nov; 112(5):1141-50. doi: 10.1016/j.prosdent.2014.05.006.

28. Ferracane JL. Resin composite-state of the art. Dent Mater. 2011 Jan;27(1):29-38. doi: 10.1016/j.dental.2010.10.020.

29. Ruse ND, Sadoun MJ. Resin-composite blocks for dental CAD/CAM applications. J Dent Res. 2014 Dec;93(12):1232-4. doi: 10.1177/0022034514553976.

30. El Ghoul WA, Özcan M, Ounsi H, Tohme H, Salameh Z. Effect of different CAD-CAM materials on the marginal and internal adaptation of endocrown restorations: An in vitro study. J Prosthet Dent. 2020 Jan;123(1):128-34. doi: 10.1016/j.prosdent.2018.10.024.

31. Cerqueira CL, Kappler R, Cavalcanti AAN, Lima EMCX. Marginal adaptation of provisional crowns made of acrylic and bisacrylic resins using different impression materials. Braz J Oral Sci. 2019;18:e191603. doi: 10.20396/bjos.v18i0.8657257.

32. Nejatidanesh F, Lofti HR, Savabi O. Marginal accuracy of interim restorations fabricated from four interim autopolymerizing resins. J Prosthet Dent. 2006 May;95(5):364-7. doi: 10.1016/j.prosdent.2006.02.030.

33. VOCO GmbH. Grandio Blocks. Cuxhaven, Germany; 2018 Jan [cited 2019 Oct 11]. Available from: https://www.voco.dental/br/portaldata/1/resources/products/instructions-for-use/e1/grandioblocs_ifu_e1.pdf.

34. FGM Dental Group. Brava Bloc Amann.Joinvile, SC: FGM; c2020 [cited 2019 Oct 11]. Available from: https://www.fgm.ind.br/site/wp-content/uploads/2018/02/perfil_brava-block.pdf.

35. 3M. Lava Ultimate. In: Catálogo Técnico de Produtos 3M Oral Care [cited 2019 Oct 11]. p.28. Available from: http://dentalprimecwb.com.br/wp-content/uploads/2017/09/AtualizadoCat\%C3\%A1logo-T\%C3\%A9cnico-de-Produtos-3M.pdf.

36. das Neves FD, Carneiro TAPN, do Prado CJ, Prudente MS, Zancopé K, Davi LR, et al. Micrometric precision of prosthetic dental crowns obtained by optical scanning and computer-aided designing/computer-aided manufacturing system. J Biomed Opt. 2014 Aug;19(8):088003. doi: 10.1117/1.JBO.19.8.088003. 